\title{
Técnica para el radio-diagnóstico de las fracturas claviculares
}

\author{
POR EI, NOCTOR \\ FORTUNATO QUESADA \\ Profesor suplente de Clínica Propedética Quirúrgica, \\ en la Facaltad de Medicina de Lima
}

Cuando se sigue el método corri-ntemente adoptado para hacer un radio dingnóstico en los casos de la fractura de la clavícula, que consiste en tomar una radiografía en el sentido frontal, centrando los rayos en el punto medio de la clavícula o imprimiendo dos placas conforme at la técnica estereoscópica, las fallas que se puede's observar son muy notables.

A fin de confirmar esto, vamos a revisar ties especímenes, tomados al acaso, ell los que hemos podido comparar los datos madiológicos con nuestras constaciones operatoriıs.

En el primer caso (fig. 1) se tomaron estereoscópicas que inspeccionamos en el negatoscopio bilocular: Sobre los cabos cabalgados de los tragmentos claviculares ( $a \mathrm{yb}$ b) podian percibirse dos pequeñas manchas (c y d), que fueron interpretadas como ligeras esquirlas superpuestas de canto. El diagnóstico radiológico fue: fracturá de la clavícula, a dos fragmentos principales, condos conminutas insignifican. tes. Cuando operamos al sujeto, encontramos el hueso roto en cinco pedazos, de los cuales tres no los sospechábamos ni en su magnitad ni en su distribución (uno de ellos, de 3 $\mathrm{cm}$. de latgo por $12 \mathrm{~mm}$. de ancho, lo conservamos). Quedamos bastante disgustados de este resultado diagnóstico.

- Publicado en el «urgery. Gynecology and Obstetricsn; vol. XLII, No 3 , marzo 1926, pág. 424. 
El segundo caso (fg. 2), que examinamos con la experiencia-muy presente-del caso anterior, fue barto semejante. La radiografía sencilla no permitía descubrir otro detalle que la forma, en pico de flauta, de ambos fragmentos (a y b) cábalgados de la clavícula tracturada. Operamos a es. te paciente, y encontramos el hueso partido también en cin. co fragmentos: dos grandes y tres pequeños. Era una nue. va falla radio diágnóstica.

El tercer caso (fig. 3) nos dejo apreciar en la placa, una clavícula tracturada sin desplazamiento o en madera verde. Esta imagen resultába tanto más inexactá, cuanto que, a la simple explorración clínica por inspección de la región y, me. jor, por su palpación, se notaba un fíauco cabalgámientode los fragmentos. Cuandoverificamos la intervencion cruen. ta, levantando el colgajo que siempre acostumbramos en es. tos casos, pudimos ver que la superposición de las extremi. dades era graude; como se puede certificar aun en lá fotogra. fía del foco operatorio (fig. 4). Confirmamos, una vez, los errores a que nos conduce la técnicá clásica.

¿Cómo descubrir en el cáso de la clavícula fiacturada, el número exacto de los fragmentos, la orientación del trazode fractura, el grado de cabalgamiento, su distribución, etc.? Cuando se trata de otros huesos largos (el hamero, lat tibia, por ejemplo), se estudian perfectamente bien tales datos, por medio de dos radiografias perpendiculares: lo que no se sospecha en el sentido antero-posterior, se encuentra facilmente en la posición lateral y viceversa. Si en el casodela clavícula quisiéramos aplicar igual procedimiento, tendríamos que

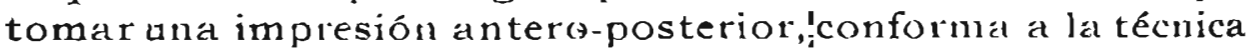
clásica, y, vistá lá imposibidad de conseguir una ell posición lateral, otra vertical colocando el foco encima del hombro y la placa debajo del asiento, y esto es dificil de realizar eficazmente. Pensamos, entonces, en aprovechar para el radiodiagnósticoclavicular, del empleode la proyección oblicua de los rayos y, logrando tomar dos radiografías con rayos pro. yectados en ángulo recto, encontrar el equivalente de las dos posiciones perpendiculares de observación de los otros huesos de los miembros, del tronco y de la cábeza.

Esto lo hemos conseguido, con toda precision, mediante un instrumento que está constituído ( $f g .5$ ) por un cuadran. te de $90^{\circ}(a)$, en cuyos extremos van montadas dos ramas perpendiculares: una (b) que entra y sale, deslizando en un soporte acanalado, (c) que lleva además una escotadura(d). 
para encajarse en el relieve clavicular; y otra (e) deslizable igualmente en un soporte acanalado más pequeño que puede correr a lo largo del cuadrante y cuyo reducido tamaño permite la inclusión del hombro, por áncho que sea, en la abertura (f) que deja.

El dispositivo sencillo que hemos ileado, se explica claramente en el esquema siguiente ( $6 g .6)$ : El sujeto que se examina (a) es colocado sobre la mesa en el decubito ventral, una placa (b-b) se incluye por debajo de lá región clavicular (c), centramos los rayos del foco A según el eje de la rama $b$ del aparato, y tomamos la primera radiogratial, de arriba-abajo, esto es, de lá cábeza (d) al tronco (e); luego cambiamos de placa (si es grande, la separamos en dos mitades cun un imperméable) y centramoslos rayos del foco B. siguiendo el eje de la rama e de la a madura, e impresionamos una segunda radiografia, de abajo-ariba, vale decir, del tronco (e) a la cabeza (d). Cuando se toma la primera radio, hay que cuidar de correr la placa un poco hacia el tórax y lo contrario al impresionar la segunda.

El primer caso en que ensayamos esta téenica, lo hicimos en compañáa de mi amigo el radiologo doctor Eládio LANatra, el 0 de octubre de $192 \mathrm{t}$. Elegimos un sujeto que llevaba en su clávículá derecha una grapa de DUJa RIER, elemento de reparo precioso para la circunstancia de probar si eran debidamente logradas las dos posiciones perpendiculares de la clavícula. Era menester también comparar los resultados por obtener, con los que se consiguen con la técnica usual. Radiografiado primeramente según ésta, obtuvimos el negativo (fig. 7) de una síntesis (a) aceptable, con ligera separación de los fragmentos (b y c) y la grapa en imagen oblicua. Las radios, obtenidas conforme a la técnica indicada por nosotros, dieron imágenes muy interesantes: por una parte (fg. 8), en la tomada de arriba-abajo (posición A del tubo Je la fg. 6) vemos la grapa (d) de frente, con todos sus detalles, hasta las escotaduras (a) de fijación, en ausencia completá de síntesis ósea, agarrada integramente por una de sus ramas al fragmento interno (c) y absolutamente escapada del externo (b), las dos mitades de la clavícula cabalgadas ampliamente $y$ vistas por suborde lineal; por otra parte (fg. 9), en la impresa de abajo-arriba (posición B del tubo de la fig. 6) encontramos la grapa perfectamen te de costado (d), reconocible sólo por uno de sus lados, por su lomo, y como formando parte de una síntesis ósea (a) ideal 
y montada sobre la sombra (b c) de la cláícula sorprendida por su cara incurvada en $S$, sin sospechar siquiera el ca. balgamiento amplio existente.

Se puede, pues, -como lo demostramos ante la Sociedad Peruana de Cirugín, en su sesión de 15 de octubre de 1924tomar radiografías de la clavícula en dos posiciones perpendiculares, tal cual se hace con los demás huesos, lo que nos permitirá estudiar mejor la anatomía patológico-radiológicá de sus fracturas u otras lesiones, y controlar debidamente su estado post-operatorio. Demostraremos también que ias imágenes reproducidas no eran deformaciones claviculatres: desde luego, por la exactitud en el retrato de la grapa, y, al su vez, con mayor importancia, por las sombras de la clavícula normal del otro hado, que refiejaban los aspectos rque estamos acostumbrados a mirar ell la anatomía ciásica de este hueso; mientras que en la radiografia tomada de arriba-abajo (fig. 1O) a parece vista por su borde lineal (A) como una recta, tal cual se la ve de perfil en Osteologia; en camhio, en la impresionada de abajo arriba (fg. I1) la encontramos incurvada en $\mathrm{S}$. como cuando la observamus esquelética de flente por una de sus caras. Pusteriormente hemos operado a este individuo, para extraterle el elementode sintesis que, desplazado, le molestaba, y pudimos ratificarla exactitud de nuestras anotáciones maliológicas.

El siguiente caso tue tomado por nosotros para ensayar la exactitud de un diagnostico pre-operatorio verificado por nuestro procedimiento, pues estando indicada en El la intervención cruenta, podíamos realizar de visu la demostración anátomo patologica operatoria. Naturalmente, para com. parar, tomamos previamente una radio antero-posteriorcoriente y dos estereoscópicas. La radiografia según lá téc. nica clásica nos mostró ( $f g .12$ ) un fragmento interno (a) en bisel y otro externo (b) con escrtádura. Nấa más. Lá estereoscopica nos reveló (fig. 13) los mismos fránmentos (a y b), y poliamos sorprender además que la rama externa (c) de la cscotalurat estaba rajada. Estos datos radiológicos no explicaban un hecho clínico que saltaba en el caso e imponía lá intervención: se sentía nu fágmento puntiagudo que amenazaba perforar la piel de la región. Las radios tomadas perpendicularmente nos dieron un resultaclo más completo y lógico: en lá tomada de la cabezát al tronco (posición A del tubo de la fig. 6) ballamos (fig. 14) un frágmen. to interno (a) biselado y fuertemente cabalgado sobre otro 
extremo (b) también en bisel y, ademas, uno tercero volante (c.d) alargado y vertical, con el borde de afuera (e) recto y el de adentro(f) convexo, con sus extremidades (c y d) puntiagudas y la superior (c) amagando la sombra de la piel, con una extensión, más o menos, de $5 \mathrm{~cm}$. de largo porx $1 \mathrm{~cm}$. de ancho; en la impresionada del tronco a la cabeza (posicion B del tubo de la fig. 6) encontramos (fig. 15) los mismos tragmentos (a y b) cabalgados en el sentido anteroposterior, con sus biseles algo obtusos, y, descollando sobre las sombras de ellos, una mancha bien obscura (c) que no era sino la silueta del tercer fragmento tomado en su corte longitudinal, permitiéndonos apreciar su espesor y su colocacion por delante del foco principal de fractura. Podiamos hacer un diagnóstico radiológico completo y de acuerdo con las observaciones clínicas. En la operación, cuando levantamos la charuela de partes blandas se present6 a nuestra vista y a la de los que nos hon raban con su presencia-entre ellos, el Decano de la Fácultad de Medicina, doctor Guillermo Gastañera-un panorama de la zona de fractura, exactamente calcado sobie la imagen de la vadiografia de la fig. 14: los dos fiagmentos biselados y el tercer fragmento, que lo tuvimos en nuestros manos, por delante, verticalmente orientado hacia la superficie cutánea y con las características de dimensiones que habíamos calculado sobie la placa.

Tenemos otros casos confirmatorios. De todos modos, creemos, como nos lo expresára el cirujano y radiólogo doctor James T. CASE, a su paso por Lima, que este procedimiento original tiene resultados incontrovertibles superiores a los obtenidos con la técnica clásica y presenta sobre la es. tereoscópica la gran ventaja de poder ser tenido en la sala de operaciones a la vista del cirujano para su revisión directa durante la intervención.

RES U M N :

El autor presentá algunos casos de radio-diagnóstico clavicular de distintos radiólogos, según la técnica clásica, y compura lo previsto en las radiografias con las constataciones operatorias, llegando a la conclusion que el cirujano está entonces siempre expuesto a encontrar más de lo que dicen los rayos $\mathrm{X}$, a pesar de emplear la estereoscó pica, que era el procedimiento de elección hasta hoy.

Presenta los resultados obtenidos en las experiencias que 
ha llevado a cabo, tomando radiografías claviculares en án. gulo recto, para lo que se ayıda de un cartabón fabricado especialmente con ese objeto. Cree así, por el testimonio de los documentos conseguidos, que las radiografias tomadas conforme a la fórmula propuesta ilustran claramente sobre el estado de las lesiones, principalmente en lo que se refiere al cabalgamiento de los fiagnentos mayores y al numero $y$ disposición de los menores. Demuestrá que las radiografías en ángulo recto reproducen la anatomía normal de la claví. cula $y$ retratan exactamente el tamaño de los segmentos fracturados. Las constataciones operatorias ban venido a apoyar las conclusiones anteriores.

El autor cree que las radiografías en ángulo recto constituyen en el caso de la clavicula un procedimiento exacto de radio diagnóstico y deben ser llevadas a cabo para juzgar exactamente de los resultados de un tratamiento por tractura clavicular. A esto se agrega la ventaja que el operador puede observar las radiografias durante la operación, lo que no ocurre con las estereoscópicas. 

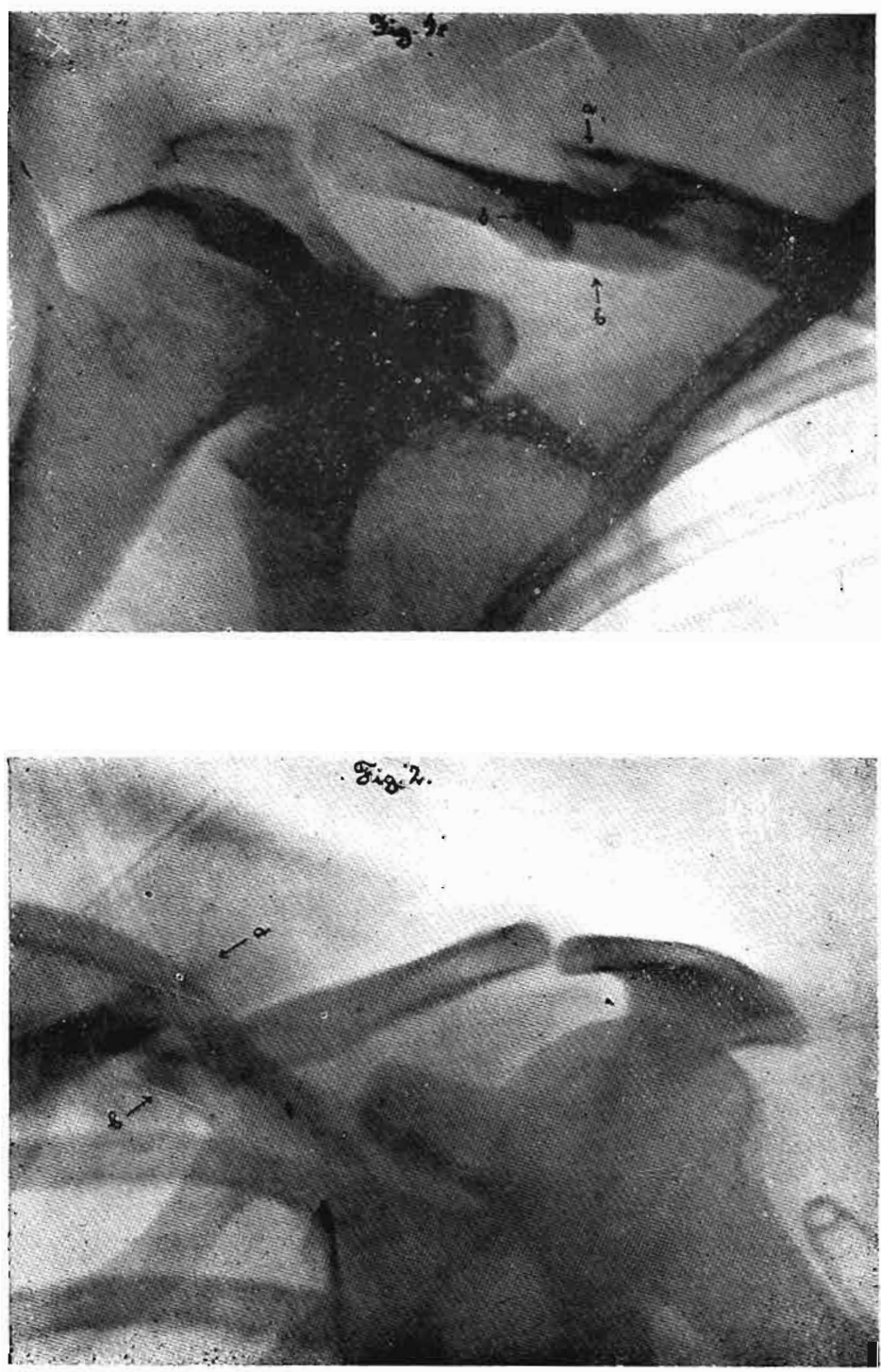

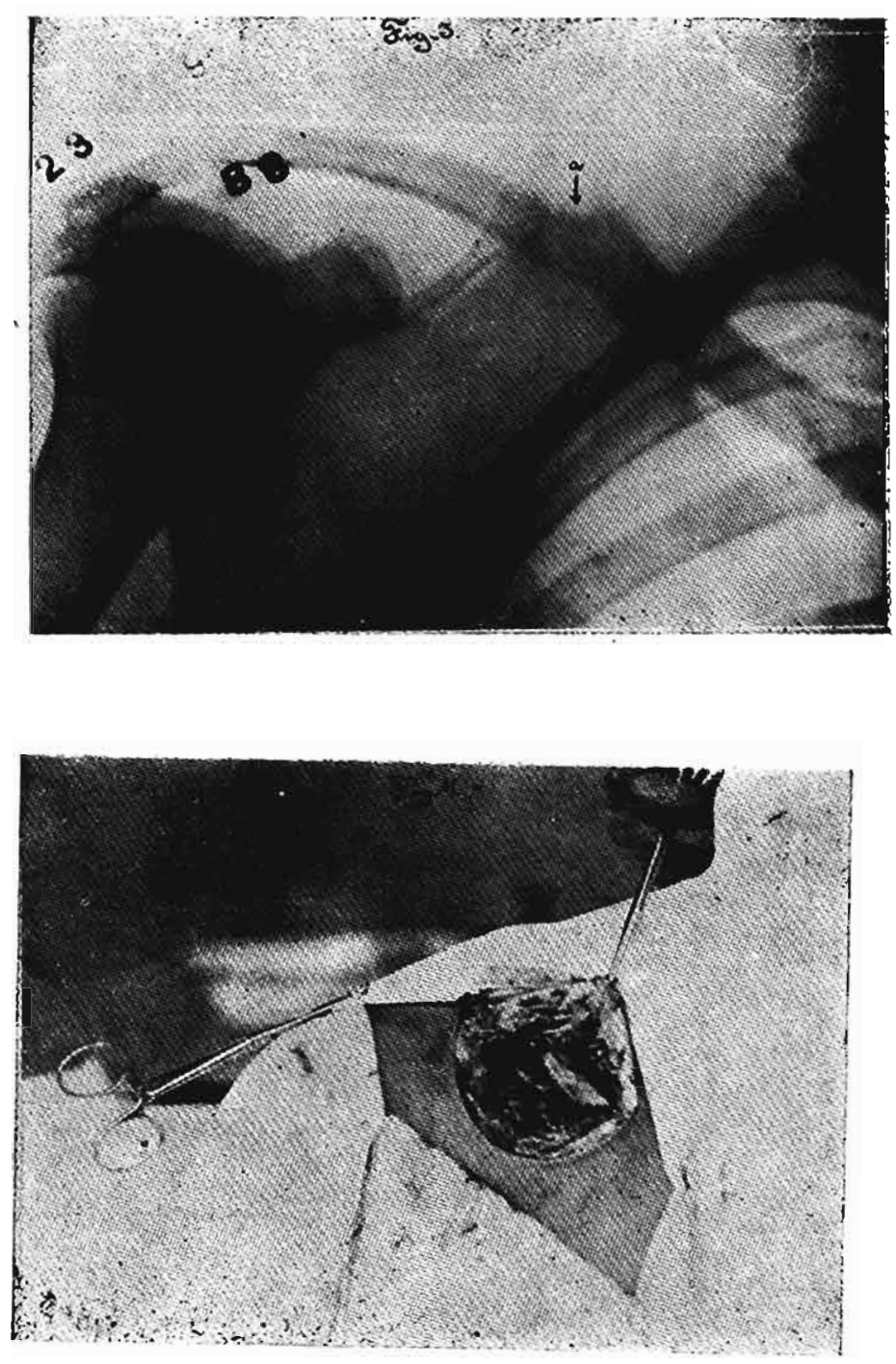

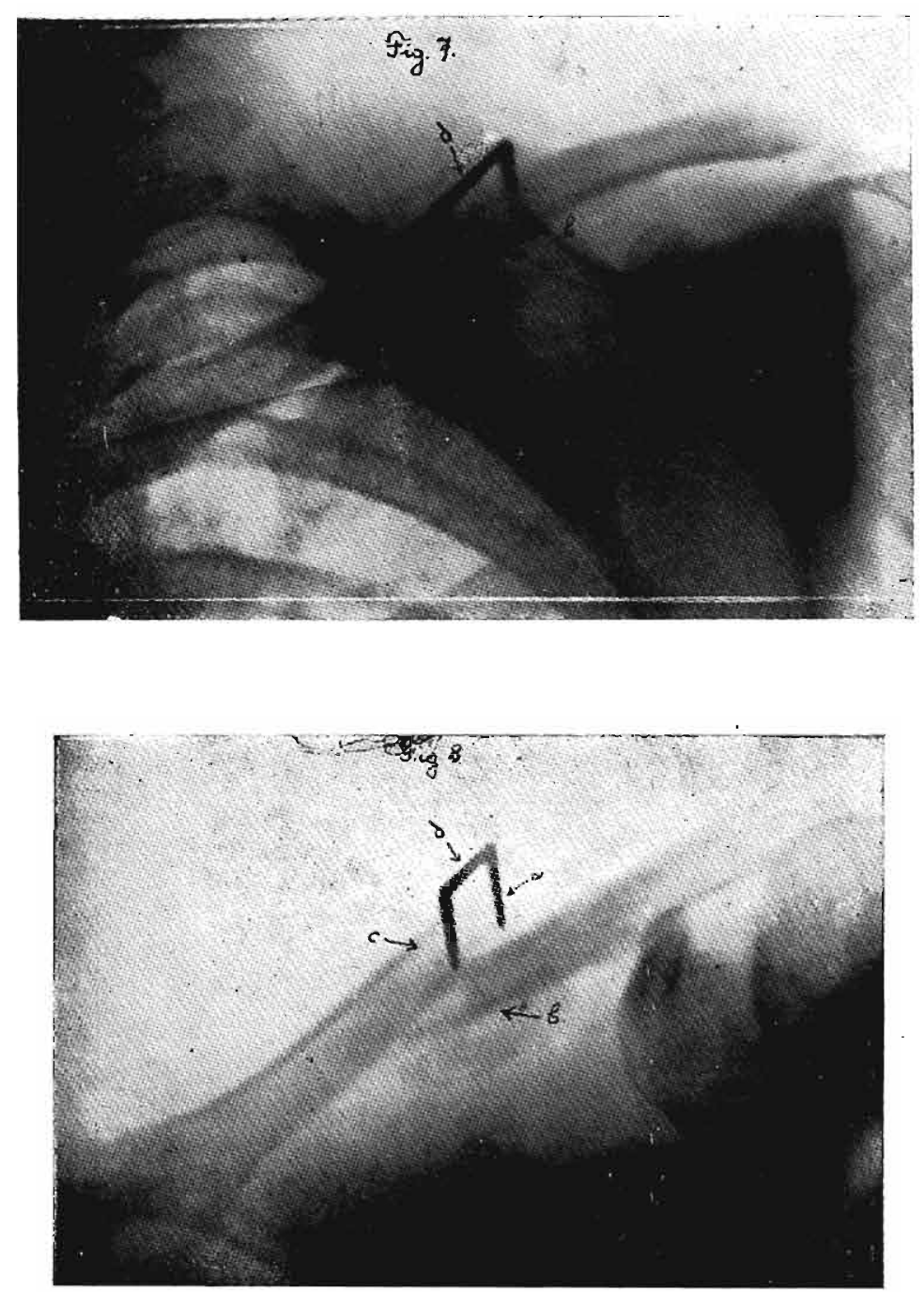

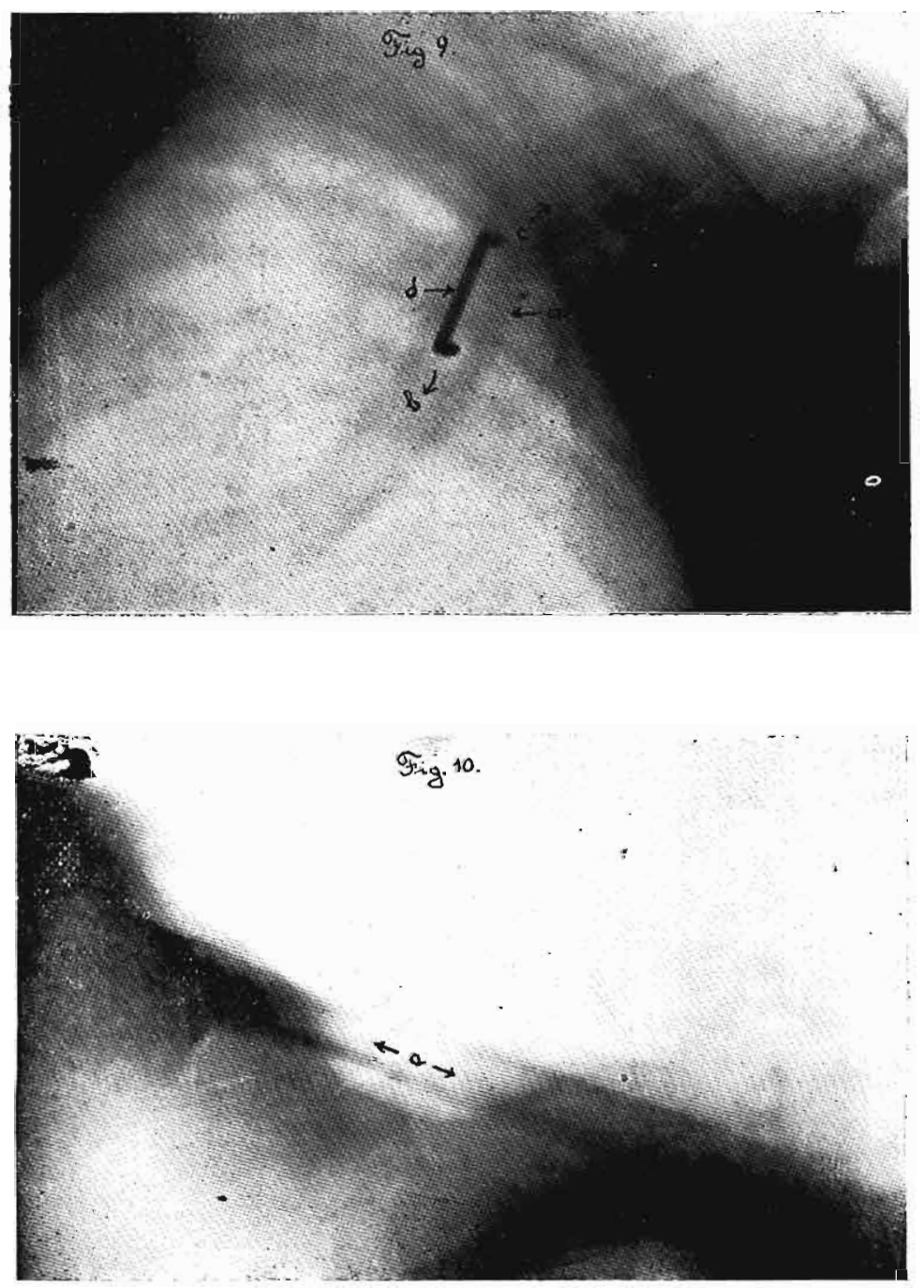

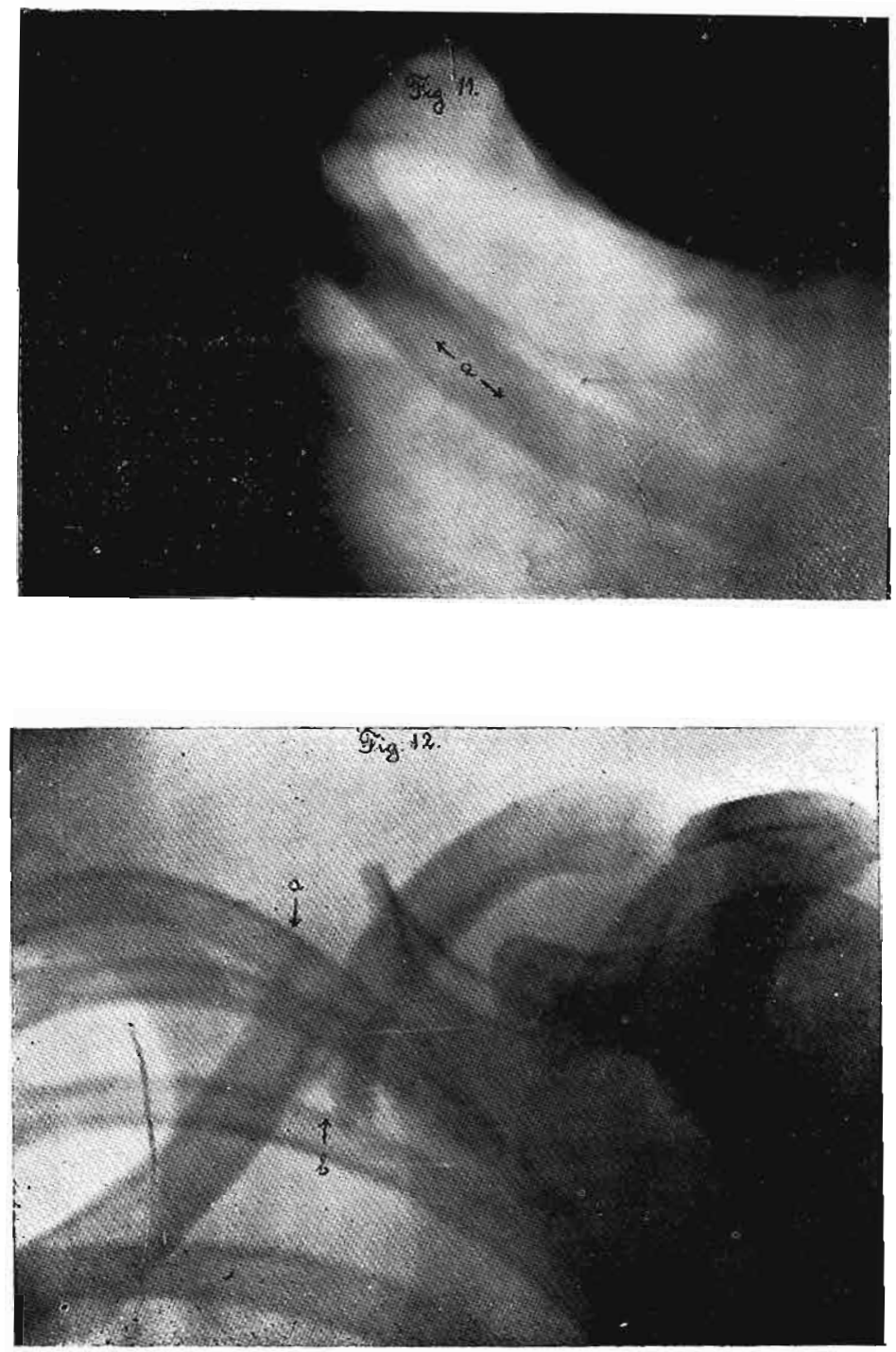

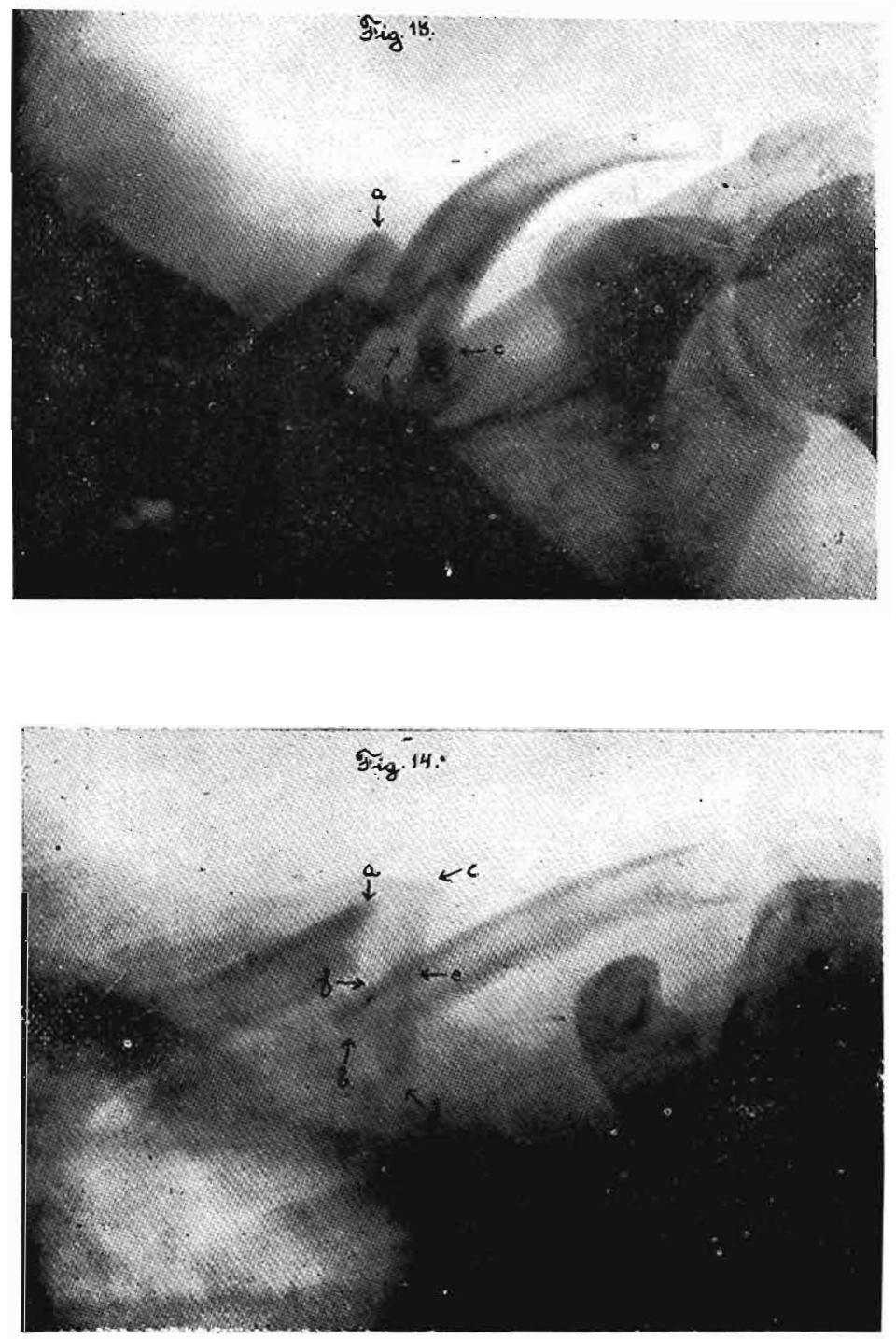

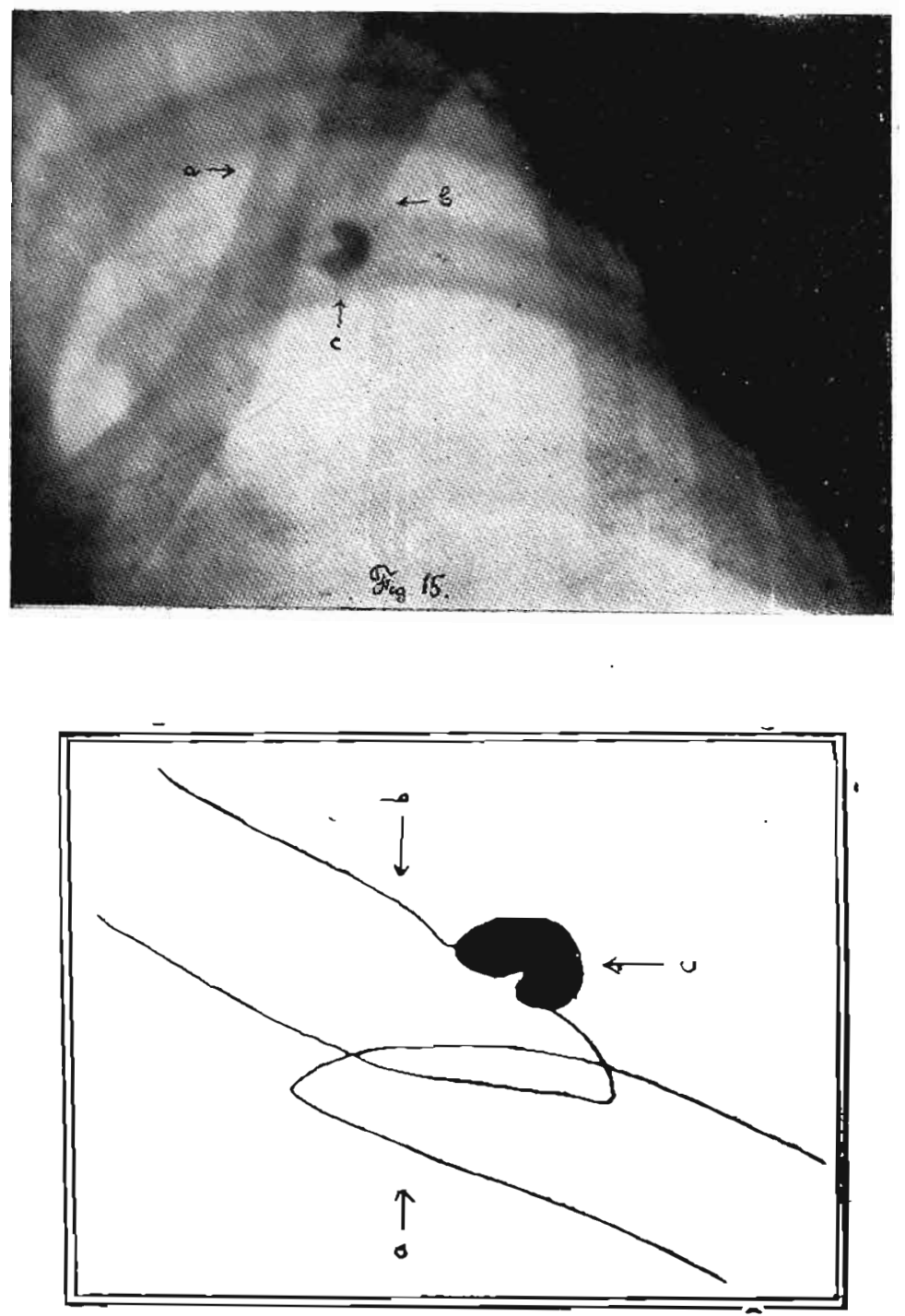

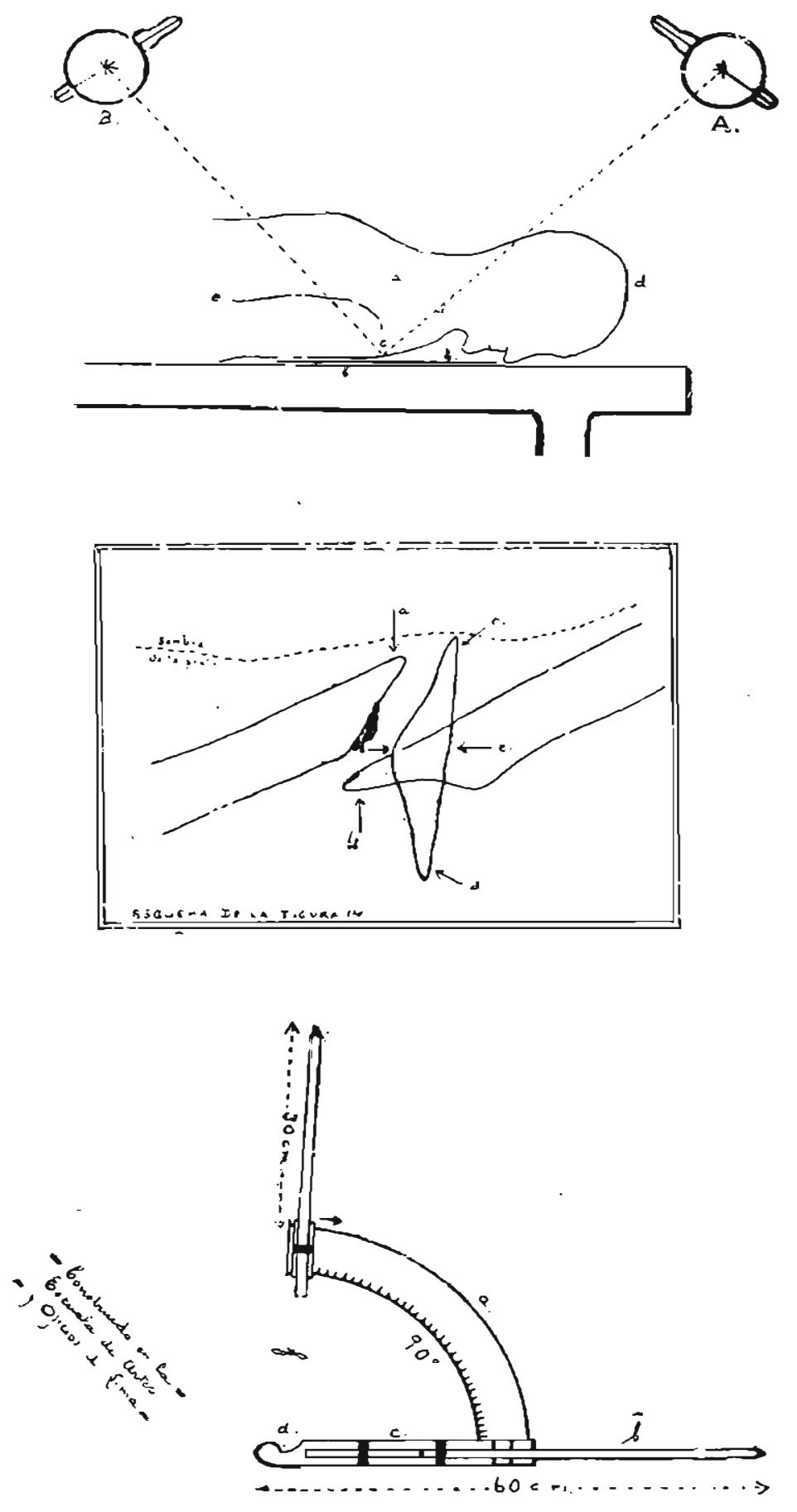